\title{
Curative Therapies for Sickle Cell Disease
}

\author{
Kirshma Khemani, MD, ${ }^{1,2}$ Deeksha Katoch, MBBS, ${ }^{1,2}$ Lakshmanan Krishnamurti, MD ${ }^{1,2}$ \\ ${ }^{1}$ Department of Pediatric Hematology-Oncology-Bone Marrow Transplant, Aflac Cancer and Blood Disorders Center, Emory University \\ School of Medicine, Atlanta, GA ${ }^{2}$ Children's Healthcare of Atlanta, Atlanta, GA
}

Background: Sickle cell disease (SCD) is an inherited hemoglobinopathy associated with severe morbidity, impaired quality of life, and premature mortality. Hematopoietic stem cell transplantation (HSCT) is the only curative treatment available for patients with SCD and has a $>90 \%$ event-free survival when a matched related donor is used. However, availability of human leukocyte antigen (HLA)-identical sibling donors for the SCD population is limited. The use of HLA-matched unrelated donors or related haploidentical donors has the potential to expand the donor pool.

Methods: We reviewed the current literature on the indications for SCD transplantation, donor options, and the emerging use of gene therapy as a treatment option. Google Scholar and PubMed were searched using the terms SCD, bone marrow transplantation, donor sources, gene therapy, HSCT, and HLA matching. Additional articles were identified from the bibliographies of retrieved articles. All articles were reviewed for pertinent information related to SCD and transplantation.

Results: HSCT has the potential to establish donor-derived normal erythropoiesis with stable long-term engraftment, amelioration of symptoms, and stabilization of organ damage. The majority of HSCT has been performed in children from HLA-identical sibling donors and has resulted in excellent rates of survival. The use of alternate donors such as HLA-matched unrelated donors and haploidentical donors has the potential to expand the applicability of HSCT for SCD. Early results in gene therapy for SCD are encouraging.

Conclusion: Evaluation of the long-term benefits of curative therapies for SCD requires comparative clinical trials and studies of late effects.

Keywords: Anemia-sickle cell, bone marrow transplantation, genetic therapy, stem cell transplantation

Address correspondence to Lakshmanan Krishnamurti, MD, Department of Pediatric Hematology-Oncology-Bone Marrow Transplant, Aflac Cancer and Blood Disorders Center, Emory University School of Medicine, 2015 Uppergate Drive, Suite 400, Atlanta, GA 30322. Tel: (404) 785-0914. Email: Ikrishn@emory.edu

\section{INTRODUCTION}

Sickle cell disease (SCD) is the most commonly inherited hemoglobinopathy. The global number of neonates affected by SCD is 312,000; in the United States, the estimated number of people with SCD is 100,000 , with an estimated incidence of 1 in 365 African American births and approximately 1 in 16,300 Hispanic American births. ${ }^{1-3}$ The disease is associated with severe complications including vaso-occlusive crises, acute chest syndrome, splenic sequestrations, neurologic events, substantial morbidity, and premature mortality. Disease-modifying therapies such as hydroxyurea and chronic blood transfusions can reduce the rate of complications and may prolong survival, but hematopoietic stem cell transplantation (HSCT) is the only therapy with curative intent. ${ }^{4}$ In 1984, the first report of HSCT in a patient with SCD who was transplanted for acute myelogenous leukemia demonstrated the efficacy of HSCT as a curative treatment option for SCD patients with severe disease. ${ }^{5}$ In 1996 , Walters et al first reported the curative benefits of human leukocyte antigen (HLA)-identical sibling donor HSCT in 22 patients with severe SCD. ${ }^{6}$ HSCT has since been demon- strated to result in the long-term cure of SCD with amelioration of clinical manifestations and stabilization of organ function. ${ }^{7-9}$

Since 2006, HSCT has been performed on large numbers of young patients with SCD, and this increase in the number of patients, together with the increase in supportive care, may explain the improved outcomes. ${ }^{10}$

Although HSCT holds promise as a cure for SCD, treatment-related complications limit its broad acceptability and applicability. The potential for graft rejection, infections, prolonged immunosuppression, acute or chronic graft-vshost disease (GVHD), and disease relapses are essential considerations before opting for HSCT. The limited availability of suitable donors and the decisional dilemma posed by the complex tradeoffs between disease-related and treatment-related morbidity and mortality are other common barriers. ${ }^{6,11-13}$ The advent of alternate donor transplantation and clinical trials of gene therapy offer hope for a curative treatment for an increasing number of patients who may have been excluded for the lack of a matched donor. 
Table 1. Limitations of Hematopoietic Stem Cell Transplantation by Donor Type

\begin{tabular}{ll}
\hline \multicolumn{1}{c}{ Type of Donor } & \multicolumn{1}{c}{ Limitations } \\
\hline HLA-matched sibling & Paucity of fully matched donors \\
Matched unrelated donor & Paucity of donors \\
& Increased risk of GVHD \\
Haploidentical donor & Increased risk of graft rejection and GVHD \\
Umbilical cord blood from & Paucity of donors \\
sibling or unrelated donor & Limited use for young adults \\
& High rate of nonengraftment in unrelated umbilical cord blood transplants \\
& Utility limited by the recipients' body weight \\
\hline
\end{tabular}

GVHD, graft-vs-host disease; HLA, human leukocyte antigen.

This article provides an overview of the current practice of HSCT in patients with SCD and highlights some of the key emerging trends in gene therapy. We searched Google Scholar and PubMed using the terms SCD, bone marrow transplantation, donor sources, gene therapy, HSCT, and HLA matching. Additional articles were identified from the bibliographies of retrieved articles.

\section{INDICATIONS FOR HEMATOPOIETIC STEM CELL TRANSPLANTATION}

In the first clinical trial conducted in the 1990s, HSCT was reserved as a treatment option for patients with severe complications of SCD such as stroke and for patients who were considered to be at risk for long-term disease-related complications associated with multiple hospitalizations for pain crises or acute chest syndrome. In the original report by Walters et al, the indication for HSCT was stroke in $57 \%$ of patients and pain in only $23 \%$ of patients. ${ }^{6}$ In contrast, in a 2016 study, pain is reported as the indication for HSCT in $41 \%$ of patients. ${ }^{14}$ These data suggest that patients are increasingly seeking HSCT because of the impact of recurrent acute and possibly chronic pain on their quality of life.

The age at which to conduct transplantation is a dilemma for transplant physicians. Enough evidence from the literature suggests that transplants at an early age are associated with better outcomes. Gluckman et al reported that the main predictors of event-free survival in HLA-identical sibling donor HSCT were patient age and performance of HSCT after 2006. ${ }^{10}$ Excellent 5-year overall survival (95\%) and event-free survival (93\%) were shown in transplanted patients $<16$ years of age. The 5 -year probability of GVHDfree survival was reported to be $86 \%$ in the same age group of patients. Bernaudin et al noted that age $<15$ years was a significant determinant in the overall survival of patients. ${ }^{8}$

No randomized controlled trials have compared HSCT with nontransplant treatment therapies such as hydroxyurea; however, favorable long-term survival has been reported on hydroxyurea. ${ }^{15,16}$ This relatively low toxicity therapy should be weighed against the continuous increase in morbidity with age associated with an impairment of quality of life and risk of premature mortality in SCD patients. ${ }^{17,18}$ An ongoing trial (NCT02766465, BMT CTN 1503) will provide results for comparison of bone marrow transplantation, hydroxyurea, and chronic blood transfusions in adolescents and young adults. The estimated study completion date is March 2023.
Taking these trends into account, an international panel of experts convened on behalf of the European Society for Blood and Marrow Transplantation (EBMT) Inborn Errors Working Party and the EBMT Pediatric Working Party recommended a less stringent set of indications for consideration of HSCT in SCD in 2014. ${ }^{19}$ According to the expert panel, (1) any young patient with symptomatic SCD who has an HLA-identical sibling donor should be transplanted as early as possible, preferably at preschool age; (2) bone marrow and umbilical cord blood from HLA-identical sibling donors are the recommended stem cell sources; (3) for patients who need to use an alternate donor source, more stringent indications are still recommended, and these patients should only have HSCT under a clinical trial and at a center where the staff are experienced in the procedure.

\section{DONOR SELECTION AND STEM CELL SOURCES}

Most of the literature about SCD transplantation concerns patients with HLA-identical sibling donors. Finding suitable donors continues to be a challenge for many patients with SCD. The probability of finding a donor is further limited by the acceptance of the level of HLA matching based on the stem cell source. Current recommendations by the National Marrow Donor Program recommend high-level matching at the HLA-A, HLA-B, HLA-C, and HLA-DRB1 loci for unrelated donors. ${ }^{20}$ Matching in all the loci is referred to as an $8 / 8$ match. As described by Eapen et al and Horan et al, an 8/8 matched HLA-identical donor is considered ideal; however, this scenario is rare for most patients with SCD. ${ }^{21-23}$ In addition to bone marrow, other stem cell sources include peripheral blood and umbilical cord blood. Furthermore, each stem cell source has its own risks for engraftment and GVHD. Limitations of HSCT by donor type are listed in Table 1.

In addition to stem cell source and HLA matching, another factor to consider for engraftment and improved survival is the cell dose of the graft. Cell dose is the total number of nucleated or CD34+ cells in the graft and correlates strongly with graft rejection. ${ }^{24} \mathrm{~A}$ high cell dose $\left(\geq 0.3 \times 10^{8} / \mathrm{kg}\right)$ in cord blood is critical for a successful outcome, especially for patients who may have one locus of mismatch. ${ }^{22,23}$

\section{CONDITIONING REGIMENS}

Patients undergo conditioning regimens before donor cells are transplanted to suppress their hematopoiesis and 
immune system to create space and allow engraftment to occur. ${ }^{25}$ Conditioning regimens are categorized as being myeloablative, reduced intensity, or nonmyeloablative.

\section{Myeloablative Conditioning Regimen}

Traditionally, myeloablative conditioning regimens consist of high-dose chemotherapy combined with radiation. In a multicenter trial, Walters and colleagues reported the effectiveness of using a busulfan, cyclophosphamide, and horse antithymocyte globulin conditioning regimen in 22 patients with SCD receiving HLA-identical sibling donor HSCT. At 4-year follow-up, the overall survival rate was $91 \%$ and the event-free survival rate was $73 \% .^{6}$ In 2007 , Bernaudin and colleagues reported a decrease in graft rejection from $23 \%$ to $3 \%$ with the addition of rabbit antithymocyte globulin. ${ }^{8}$ Because of these promising responses, additional studies have used this regimen for HLA-identical sibling donor HSCT, leading to increases in overall survival and disease-free survival of $90 \%-100 \%$ and $77 \%-100 \%$, respectively. ${ }^{9,26}$ However, given the toxicity associated with these chemotherapeutic agents, other regimens are also being explored.

\section{Reduced Intensity and Nonmyeloablative Conditioning Regimens}

Reports of SCD symptoms resolving even in patients with mixed chimerism ${ }^{27}$ suggest that complete donor chimerism is not necessary and have led to interest in using reduced intensity and nonmyeloablative conditioning regimens for this population.

These regimens aim to increase stable donor engraftment rates while decreasing toxicities such as mucositis and infections. Reduced intensity conditioning regimens are less myeloablative; however, they still require donor infusion for host hematopoiesis. True nonmyeloablative approaches, on the other hand, do not wholly eradicate host hematopoiesis and therefore offer the theoretical possibility of hematopoietic recovery without donor stem cell infusion. ${ }^{25}$ Hseih et al described reduced intensity/nonmyeloablative conditioning regimens consisting of fludarabine, alemtuzumab (used for in vivo $\mathrm{T}$ cell depletion), total body irradiation in a dose of $300 \mathrm{cGy}$, and sirolimus, and they reported no graft rejection and/or consequences of severe GVHD in 26 of 30 patients. ${ }^{28}$ The other 4 patients had temporary engraftment with subsequent rejection and disease relapse. Thus, the reduced toxicity profile of reduced intensity/nonmyeloablative therapies must be balanced against the risk of graft rejection.

\section{HUMAN LEUKOCYTE ANTIGEN-IDENTICAL SIBLING DONOR HEMATOPOIETIC STEM CELL TRANSPLANTATION \\ Bone Marrow Transplantation}

Early experience with HLA-identical sibling donors using bone marrow as the predominant source was reported in a number of studies in the late 1990s. ${ }^{6,9}$ Overall event-free survival was reported to be $85 \%$, with graft rejection and GVHD common causes of morbidity and mortality. Transplants conducted after 2000 have had a better event-free survival rate $(95 \%)$ and reduced graft rejection rates as reported by Bernaudin and colleagues. ${ }^{8}$

\section{Umbilical Cord Blood Transplantation}

The use of umbilical cord blood in patients with SCD is promising because of a lower risk of GVHD compared to bone marrow or peripheral blood. However, cord blood transplants tend to have a higher risk of graft rejection and a longer time for hematologic count recovery compared to bone marrow transplants, potentially increasing the risk for developing severe infections. ${ }^{29}$ In 2013, Locatelli et al reported the results of cord blood transplants from a cohort of patients with thalassemia and SCD in the Eurocord Registry. ${ }^{30}$ Thirty patients with SCD who received cord blood transplants had a 6-year disease-free survival of $90 \%$ vs $92 \%$ in the 130 patients who received bone marrow transplants. Of the patients who received cord blood, none developed extensive chronic GVHD or died from GVHD-related complications posttransplant. In 2014, Soni and colleagues reported co-infusing umbilical cord blood and bone marrow in patients with SCD to help with quicker hematologic count recovery. These patients had more rapid neutrophil and platelet engraftment compared to patients receiving bone marrow transplantation or cord blood transplantation alone. None of the patients developed greater than grade 2 acute GVHD or chronic GVHD. ${ }^{31}$

\section{ALTERNATIVE DONOR TRANSPLANTATION}

The lack of donor availability for patients with SCD has led to the search for alternative donor sources for HSCT. Data about treatment-related morbidities and long-term survival for patients using alternative donor sources are limited. The most common alternative sources are matched unrelated donors (using either bone marrow or umbilical cord blood) and haploidentical donors.

\section{Matched Unrelated Donors}

A common challenge related to HLA-matched unrelated donors is the degree of matching needed for a successful outcome. Two trials, Sickle Cell Transplant To Prevent Disease Exacerbation (STRIDE, NCT01565616) and Sickle Cell Unrelated Transplant trial (SCURT, BMT CTN 0601, NCT00745420), are evaluating the use of matched unrelated donors in different age groups and with different conditioning regimens. The STRIDE trial started in 2012 for reduced intensity myeloablative transplantation in patients with SCD aged 15-40 years and reported excellent outcomes (overall survival and event-free survival of $95 \%$ ) at 12-month follow-up. ${ }^{32}$ The SCURT trial opened in 2008 and demonstrated no difference in graft rejection rates with matched unrelated donors compared to HLA-identical sibling donors; however, significant morbidity from chronic GVHD (62\%) was reported. ${ }^{14}$

Unlike the good outcomes in HLA-identical sibling donor umbilical cord blood HSCT, use of unrelated umbilical cord blood has yielded negative outcomes, causing one of the first studies to close prematurely. ${ }^{33}$ In another study, 16 patients with SCD were transplanted with an unrelated single cord blood unit; the overall survival rate was $94 \%$, but disease-free survival was only $50 \%$ and overall mortality was $15 \% .^{34}$ Some of the limitations when considering unrelated cord blood are the need for an adequate cell dose and the delay in red blood cell and platelet engraftment that can increase morbidity and mortality post-HSCT. ${ }^{35}$ Established 
Table 2. Indications for Hematopoietic Stem Cell Transplantation from Matched Unrelated Donors for Patients with Sickle Cell Disease ${ }^{6,35-37}$

\begin{tabular}{|c|c|}
\hline Established Indications & Potential Indications \\
\hline Neurologic symptoms & Neurologic sequelae from silent infarcts \\
\hline \multicolumn{2}{|l|}{ - Overt stroke } \\
\hline \multicolumn{2}{|l|}{ - High transcranial Doppler velocity (>200 m/s) } \\
\hline Cardiac/pulmonary symptoms & Tricuspid regurgitation velocity $>2.5 \mathrm{~m} / \mathrm{s}$ \\
\hline $\begin{array}{l}\text { - Acute chest syndrome ( } \geq 1 \text { episode while on a therapeutic dose of } \\
\text { hydroxyurea) }\end{array}$ & Pulmonary hypertension \\
\hline \multicolumn{2}{|l|}{ Bone/joint symptoms } \\
\hline \multicolumn{2}{|l|}{ - Avascular necrosis/osteonecrosis (usually $\geq 2$ joint involvement) } \\
\hline Renal/genitourinary symptoms & Renal insufficiency (need for dialysis, nephrotic syndrome) \\
\hline \multicolumn{2}{|l|}{ - Recurrent priapism requiring medical management } \\
\hline \multicolumn{2}{|l|}{ Hematologic symptoms } \\
\hline \multicolumn{2}{|l|}{$\begin{array}{l}\text { - Red cell alloimmunization from recurrent packed red blood cell } \\
\text { transfusions }\end{array}$} \\
\hline \multirow[t]{2}{*}{ Hepatic symptoms } & Iron overload \\
\hline & Sickle-related liver injury \\
\hline \multicolumn{2}{|l|}{ Vaso-occlusive crisis } \\
\hline $\begin{array}{l}-\geq 2 \text { hospitalizations for pain management despite being on therapeutic } \\
\text { dose of hydroxyurea }\end{array}$ & \\
\hline
\end{tabular}

and potential indications for patients with matched unrelated donors are listed in Table 2.6,35-37

\section{Haploidentical Donors}

Because the probability is quite low that most patients with SCD will find an HLA-identical sibling donor, the use of haploidentical donors has the potential to substantially expand the pool of potential donors. One of the largest studies was conducted at Johns Hopkins where 14 patients with SCD (the majority being adults) were transplanted using haploidentical donors. ${ }^{38}$ The pretransplant conditioning regimen included cyclophosphamide, antithymocyte globulin, fludarabine, and 200 cGy total body irradiation, with the addition of post-transplant high-dose cyclophosphamide to target and destroy proliferating $T$ cells. Approximately half the patients had good donor engraftment; however, the graft rejection rate was $43 \%$, an unacceptably high rate for haploidentical transplantation. None of the patients developed acute or chronic GVHD, and no deaths were reported. A study at St. Jude's Children's Research Hospital by Dallas and colleagues had a smaller haploidentical cohort $(n=8)$; they reported an overall survival rate of $75 \%$ and diseasefree survival rate of $38 \%$ at 2 years post-HSCT. ${ }^{39}$ Four patients developed acute GVHD limited to grades 1 and 2. Two of the four patients died from the complications of chronic GVHD.

The low HSCT success rates with haploidentical donors compared to HLA-identical sibling donors and the high rates of GVHD warrant further investigation, focusing specifically on reducing graft rejection.

\section{COMPLICATIONS AFTER HEMATOPOIETIC STEM CELL TRANSPLANTATION}

Because of exposure to conditioning regimens and their effects on different organ systems, HSCT is associated with a host of complications. Multiple factors, including type of donor and stem cell source, pretransplant morbidities, and prolonged immune suppression, can influence the severity of these complications.

\section{Graft-vs-Host Disease}

GVHD is the most common complication associated with HSCT and is generally categorized as acute (within the first 100 days post-HSCT) or chronic (after the first 100 days); however, overlap can occur, so these categorizations are not definitive. GVHD occurs when the donor T cells perceive the recipient cells as foreign antigens and attack the cells, leading to significant acute and long-term side effects. For patients with SCD, the incidence of GVHD is decreased because most patients undergo matched sibling donor HSCT. However, organ damage that may have occurred secondary to underlying SCD predisposes patients with SCD to more severe and debilitating forms of GVHD compared to non-SCD patients. ${ }^{4}$ The incidence rates for acute or chronic GVHD vary depending on donor type and age at transplant. In a study of HLA-identical sibling donors, Gluckman et al reported a cumulative incidence of $14.8 \%$ of patients developing grade 2-4 acute GVHD and an incidence of $14.3 \%$ of chronic GVHD with a $4 \%$ increase in hazard ratio with every 1-year increment in age at transplantation. ${ }^{10}$ In a trial of unrelated bone marrow transplantation, the authors 
noted an incidence of $28 \%$ for acute grade 2-4 GVHD and $62 \%$ for chronic GVHD 1 year posttransplant. ${ }^{14}$

\section{Immunocompromised State}

Steroids and other immunosuppressant agents such as cyclosporine, mycophenolate, and sirolimus are used to decrease the risk of rejection in graft recipients. These drugs compromise the immune system, putting patients at high risk of infectious complications during and after HSCT. Patients are managed with prophylactic antibacterial, antifungal, and antiviral therapies to help prevent overt infections.

\section{Infertility}

Fertility is an area of concern for many patients and their families. The risk of infertility with HSCT depends on several factors such as whether a busulfan-based conditioning regimen is used, stage of pubertal development at the time of HSCT, and exposure to radiation therapy. ${ }^{40,41}$ Busulfan is toxic to gonadal tissue and causes hypogonadotropic hypogonadism that manifests as ovarian failure and aspermatogenesis. Despite recent advancements in fertility preservation, oocyte cryopreservation and sperm banking are limited to postpubertal patients, leaving younger patients at high risk of infertility. ${ }^{42}$

\section{Secondary Malignancies}

The incidence of secondary malignancies after HSCT for SCD is not clearly defined. Factors affecting the incidence of secondary malignancies include pretransplant conditioning regimens and radiation use, prior use and cumulative dose of hydroxyurea, and presence of GVHD. Secondary malignancies can be solid tumors or $\mathrm{T}$ cell- or B cell-derived leukemia. Gluckman et al reported 2 cases of central nervous system lymphoma, and isolated case reports of ovarian tumors, renal cell carcinoma, acute myeloid leukemia, and myelodysplastic syndrome have been published. ${ }^{10,43-45}$

\section{Graft Rejection or Relapse}

The recipient's immune system can attack the foreign antigens in the donor's marrow and lead to graft rejection and disease relapse. A multitude of factors affect the rates of rejection from the donor type to the source of stem cells. Matched sibling donor transplants with the closest HLA match have the least rates of rejection compared to mismatched and alternative donors. Gluckman et al reported graft failure in 23 of 1,000 patients who received matched sibling donor transplants, while Shenoy et al reported a graft rejection incidence of $10 \%$ in patients who received HLA-matched unrelated transplants. ${ }^{10,14}$ The use of umbilical cord blood stem cells is associated with higher rates of rejection compared to other stem cell graft sources. Modifications in the conditioning regimens, such as the addition of antithymocyte globulin, has decreased the rejection rates. $^{8}$

\section{Late Effects/Complications}

In addition to acute complications post-HSCT, the potential late effects from HSCT can affect any organ system.

Cardiovascular late effects include stroke, coronary artery disease, cardiomyopathy, and congestive heart failure. The use of total body irradiation in conditioning regimens has been associated with the increased risk of dyslipidemia.
In addition, drugs such as corticosteroids and calcineurin inhibitors are associated with insulin resistance and hypertension and can also add to the risk of developing cardiovascular effects. ${ }^{46}$

Renal toxicity is associated with total body irradiation conditioning regimen and the use of nephrotoxic antibiotics, antifungals, and calcineurin inhibitors for management of acute complications and GVHD. ${ }^{47}$ Progressive loss of function may occur and may even lead to end-stage renal disease.

Radiation and chemotherapeutic drugs such as bleomycin predispose patients to pulmonary toxicities such as restrictive lung disease. Bronchiolitis obliterans can develop in association with chronic GVHD. In addition, bronchiolitis obliterans organizing pneumonia has also been described in the literature in the setting of lung infections. ${ }^{48}$

Long-term use of steroids is also associated with decreased bone mineral density and can predispose patients to fractures. Peripheral neuropathy has also been reported in patients post-HSCT.

Given the multiorgan involvement of late effects of HSCT, long-term follow-up of patients is critical for early detection of these complications to decrease morbidity and mortality.

\section{GENE THERAPY}

Gene therapy is a novel approach to providing phenotype correction as opposed to symptomatic improvement and prevention. Gene therapy provides an attractive alternative to patients who do not have an identical match while circumventing the increased GVHD complications related to haploidentical transplant. Various gene therapy strategies include (1) the addition of an antisickling $\beta$-globin gene using lentivirus, (2) fetal hemoglobin induction by BCL11A silencing, and (3) gene editing with sickle cell mutation correction using CRISPR/Cas9 or zinc finger genomic engineering tools. ${ }^{49}$ Currently, 4 phase II clinical trials using gene addition are underway in a few academic centers (NCT02247843, NCT02186418, NCT02140554, and NCT03282656).

Initial results from a multicenter trial have been encouraging. Kanter and colleagues reported preliminary data for 7 adult patients with SCD who received gene therapy with a modification of lentiviral dosing, a dose of busulfan, and mobilization of cells preharvest. ${ }^{50}$ They used the BB305 lentiviral drug product (LentiGlobin DP) that consists of autologous CD34 transduced with the BB305 vector. The BB305 vector codes for a single-point mutation (AT87Q) of the $\beta$-globin gene that in turn provides antisickling properties (similar to fetal hemoglobin) to the $\beta$-globin. In the study, all subjects successfully engrafted after receiving LentiGlobin DP, with a median time to neutrophil engraftment of 22 days (range, 17-29 days). At 7-month follow-up, the toxicity profile observed from the start of conditioning to the latest follow-up was consistent with myeloablative conditioning with single-agent busulfan. ${ }^{50}$

In addition to the current studies is a case report of a 13-year-old patient with SCD who was successfully treated with gene therapy in Paris and reported to have no adverse events. ${ }^{51}$ The protocol was extrapolated from previous gene therapy studies of patients with thalassemia.

The use of gene therapy and gene editing technologies has expanded the research potential into new curative therapies for SCD. However, further studies into delivery tools 
and safety profiles are needed to improve our understanding of these technologies.

\section{CONCLUSION}

HSCT has the potential to establish donor-derived, normal erythropoiesis with stable long-term engraftment, amelioration of symptoms, and stabilization of organ damage. The overwhelming majority of HSCTs have been performed in children with HLA-identical sibling donors and have resulted in excellent rates of survival and cure of SCD. Increasingly, the use of alternate donors such as HLA-matched donors, unrelated donors, and haploidentical donors have the potential to expand the applicability of HSCT for SCD. Early results in gene therapy for SCD are encouraging. Evaluation of the long-term benefits of curative therapies for SCD requires comparative clinical trials and studies of late effects of transplantation.

\section{ACKNOWLEDGMENTS}

The authors have no financial or proprietary interest in the subject matter of this article.

\section{REFERENCES}

1. Data \& statistics on sickle cell disease. Centers for Disease Control and Prevention. www.cdc.gov/ncbddd/sicklecell/ data.html. Updated August 9, 2017. Accessed April 9, 2019.

2. Hassell KL. Population estimates of sickle cell disease in the U.S. Am J Prev Med. 2010 Apr;38(4 Suppl):S512-S521. doi: 10.1016/j.amepre.2009.12.022.

3. Piel FB, Patil AP, Howes RE, et al. Global epidemiology of sickle hemoglobin in neonates: a contemporary geostatistical model-based map and population estimates. Lancet. 2013 Jan 12;381(9861):142-151. doi: 10.1016/S0140-6736(12)61229-X.

4. Bhatia $M$, Sheth $S$. Hematopoietic stem cell transplantation in sickle cell disease: patient selection and special considerations. J Blood Med. 2015 Jul 10;6:229-238. doi: 10.2147/JBM.S60515.

5. Johnson FL, Look AT, Gockerman J, Ruggiero MR, Dalla-Pozza L, Billings FT 3rd. Bone-marrow transplantation in a patient with sickle-cell anemia. N Engl J Med. 1984 Sep 20;311(12): 780-783.

6. Walters MC, Patience M, Leisenring W, et al. Bone marrow transplantation for sickle cell disease. N Engl J Med. 1996 Aug 8;335(6):369-376. doi: 10.1056/NEJM199608083350601.

7. Walters MC, Storb R, Patience M, et al. Impact of bone marrow transplantation for symptomatic sickle cell disease: an interim report. Blood. 2000 Mar 15;95(6):1918-1924.

8. Bernaudin F, Socie G, Kuentz M, et al. Long-term results of related myeloablative stem-cell transplantation to cure sickle cell disease. Blood. 2007 Oct 1;110(7):2749-2756. doi: 10.1182/blood-2007-03-079665.

9. Vermylen C, Cornu G, Ferster A, et al. Haematopoietic stem cell transplantation for sickle cell anaemia: the first 50 patients transplanted in Belgium. Bone Marrow Transplant. 1998;22(1):1-6. doi: 10.1038/sj.bmt.1701291.

10. Gluckman E, Cappelli B, Bernaudin F, et al. Sickle cell disease: an international survey of results of HLA-identical sibling hematopoietic stem cell transplantation. Blood. $2017 \mathrm{Mar}$ 16;129(11):1548-1556. doi: 10.1182/blood-2016-10-745711.

11. Gragert L, Eapen M, Williams E, et al. HLA match likelihoods for hematopoietic stem-cell grafts in the U.S. registry. NEngl J Med. 2014 Jul 24;371(4):339-348. doi: 10.1056/NEJMsa1311707.

12. Roth M, Krystal J, Manwani D, Driscoll C, Ricafort R. Stem cell transplant for children with sickle cell anemia: parent and patient interest. Biol Blood Marrow Transplant. 2012 Nov;18(11):1709-1715. doi: 10.1016/j.bbmt.2012.05.013.

13. Van Besien K, Koshy M, Anderson-Shaw L, et al. Allogeneic stem cell transplantation for sickle cell disease. A study of patients' decisions. Bone Marrow Transplant. 2001 Sep;28(6):545-549. doi: 10.1038/sj.bmt.1703208.

14. Shenoy S, Eapen M, Panepinto JA, et al. A trial of unrelated donor marrow transplantation for children with severe sickle cell disease. Blood. 2016 Nov 24;128(21):2561-2567. doi: 10.1182/blood-2016-05-715870.

15. Voskaridou E, Christoulas D, Bilalis A, et al. The effect of prolonged administration of hydroxyurea on morbidity and mortality in adult patients with sickle cell syndromes: results of a 17-year, single-center trial (LaSHS). Blood. 2010 Mar 25;115(12):2354-2363. doi: 10.1182/blood-2009-05-221333.

16. Steinberg MH, McCarthy WF, Castro O, et al. The risks and benefits of long-term use of hydroxyurea in sickle cell anemia: a 17.5 year follow-up. Am J Hematol. 2010 Jun;85(6):403-408. doi: 10.1002/ajh.21699.

17. Hulbert ML, McKinstry RC, Lacey JL, et al. Silent cerebral infarcts occur despite regular blood transfusion therapy after first strokes in children with sickle cell disease. Blood. 2011 Jan 20;117(3):772-779. doi: 10.1182/blood-2010-01-261123.

18. Dampier C, LeBeau $P$, Rhee $S$, et al. Health-related quality of life in adults with sickle cell disease (SCD): a report from the comprehensive sickle cell centers clinical trial consortium. Am J Hematol. 2011 Feb;86(2):203-205. doi: 10.1002/ajh.21905.

19. Angelucci E, Matthes-Martin S, Baronciani D, et al. EBMT Inborn Error and EBMT Paediatric Working Parties. Hematopoietic stem cell transplantation in thalassemia major and sickle cell disease: indications and management recommendations from an international expert panel. Haematologica. 2014 May;99(5):811-820. doi: 10.3324/haematol.2013.099747.

20. Bray RA, Hurley CK, Kamani NR, et al. National marrow donor program HLA matching guidelines for unrelated adult donor hematopoietic cell transplants. Biol Blood Marrow Transplant. 2008 Sep;14(9 Suppl):45-53. doi: 10.1016/j.bbmt.2008.06.014.

21. Dew A, Collins D, Artz A, et al. Paucity of HLA-identical unrelated donors for African-Americans with hematologic malignancies: the need for new donor options. Biol Blood Marrow Transplant. 2008 Aug;14(8):938-941. doi: 10.1016/j.bbmt.2008.06.005.

22. Eapen M, Rubinstein P, Zhang MJ, et al. Outcomes of transplantation of unrelated donor umbilical cord blood and bone marrow in children with acute leukaemia: a comparison study. Lancet. 2007 Jun 9;369(9577):1947-1954. doi: 10.1016/S0140-6736(07)60915-5.

23. Horan J, Wang T, Haagenson M, et al. Evaluation of HLA matching in unrelated hematopoietic stem cell transplantation for nonmalignant disorders. Blood. 2012 Oct 4;120(14):2918-2924. doi: 10.1182/blood-2012-03-417758.

24. Storb R, Prentice RL, Thomas ED. Marrow transplantation for treatment of aplastic anemia. An analysis of factors associated with graft rejection. N Engl J Med. 1977 Jan 13;296(2):61-66. doi: 10.1056/NEJM197701132960201.

25. Krishnamurti L. Hematopoietic cell transplantation for sickle cell disease: state of the art. Expert Opin Biol Ther. 2007 Feb;7(2):161-172. doi: 10.1517/14712598.7.2.161.

26. Locatelli F, Rocha V, Reed W, et al. Related umbilical cord blood transplantation in patients with thalassemia and sickle cell disease. Blood. 2003 Mar 15;101(6):2137-2143. doi: 10.1182/blood-2002-07-2090. 
27. Wu CJ, Gladwin M, Tisdale J, et al. Mixed haematopoietic chimerism for sickle cell disease prevents intravascular haemolysis. Br J Haematol. 2007 Nov; 139(3):504-507.

28. Hsieh MM, Fitzhugh CD, Weitzel RP, et al. Nonmyeloablative HLA-matched sibling allogeneic hematopoietic stem cell transplantation for severe sickle cell phenotype. JAMA. 2014 Jul 2;312(1):48-56. doi: 10.1001/jama.2014.7192.

29. Kekre N, Antin JH. Hematopoietic stem cell transplantation donor sources in the 21st century: choosing the ideal donor when a perfect match does not exist. Blood. $2014 \mathrm{Jul}$ 17;124(3):334-343. doi: 10.1182/blood-2014-02-514760.

30. Locatelli F, Kabbara N, Ruggeri A, et al.; Eurocord and European Blood and Marrow Transplantation (EBMT) group. Outcome of patients with hemoglobinopathies given either cord blood or bone marrow transplantation from an HLA-identical sibling. Blood. 2013 Aug 8;122(6):1072-1078. doi: 10.1182/blood-2013-03-489112.

31. Soni S, Boulad F, Cowan MJ, et al. Combined umbilical cord blood and bone marrow from HLA-identical sibling donors for hematopoietic stem cell transplantation in children with hemoglobinopathies. Pediatr Blood Cancer. 2014 Sep;61(9):1690-1694. doi: 10.1002/pbc.25085.

32. Krishnamurti L, Sullivan KM, Kamani NR, et al. Results of a multicenter pilot investigation of bone marrow transplantation in adults with sickle cell disease (STRIDE). Blood. 2015;126(23):543.

33. Kharbanda S, Smith AR, Hutchinson SK, et al. Unrelated donor allogeneic hematopoietic stem cell transplantation for patients with hemoglobinopathies using a reduced-intensity conditioning regimen and third-party mesenchymal stromal cells. Biol Blood Marrow Transplant. 2014 Apr;20(4):581-586. doi: 10.1016/j.bbmt.2013.12.564.

34. Ruggeri A, Eapen M, Scaravadou A, et al; Eurocord Registry; Center for International Blood and Marrow Transplant Research; New York Blood Center. Umbilical cord blood transplantation for children with thalassemia and sickle cell disease. Biol Blood Marrow Transplant. 2011 Sep;17(9):1375-1382. doi: 10.1016/j.bbmt.2011.01.012.

35. Fitzhugh CD, Abraham AA, Tisdale JF, Hsieh MM. Hematopoietic stem cell transplantation for patients with sickle cell disease: progress and future directions. Hematol Oncol Clin North Am. 2014 Dec;28(6):1171-1185. doi: 10.1016/j.hoc.2014.08.014.

36. Shenoy S. Hematopoietic stem-cell transplantation for sickle cell disease: current evidence and opinions. Ther Adv Hematol. 2013 Oct;4(5):335-344. doi: 10.1177/204062071348306322.

37. Angelucci E, Matthes-Martin S, Baronciani D, et al. Hematopoietic stem cell transplantation in thalassemia major and sickle cell disease: indications and management recommendations from an international expert panel. Haematologica. 2014 May;99(5):811-820. doi: 10.3324/haematol.2013.099747.

38. Luznik L, O'Donnell PV, Symons HJ, et al. HLA-haploidentical bone marrow transplantation for hematologic malignancies using nonmyeloablative conditioning and high-dose, posttransplantation cyclophosphamide. Biol Blood Marrow Transplant. 2008 Jun;14(6):641-650. doi: 10.1016/j.bbmt.2008.03.005.

39. Dallas MH, Triplett B, Shook DR, et al. Long-term outcome and evaluation of organ function in pediatric patients undergoing haploidentical and matched related hematopoietic cell transplantation for sickle cell disease. Biol Blood Marrow Transplant. 2013 May;19(5):820-830. doi: 10.1016/j.bbmt.2013.02.010.

40. Walters MC, Hardy K, Edwards S, et al. Pulmonary, gonadal, and central nervous system status after bone marrow transplantation for sickle cell disease. Biol Blood Marrow Transplant. 2010 Feb;16(2):263-272. doi: 10.1016/j.bbmt.2009.10.005.

41. Smith-Whitley K. Reproductive issues in sickle cell disease. Blood. 2014 Dec 4;124(24):3538-3543. doi: 10.1182/blood-2014-07-577619.

42. Practice Committee of American Society for Reproductive Medicine. Fertility preservation in patients undergoing gonadotoxic therapy or gonadectomy: a committee opinion. Fertil Steril. 2013 Nov;100(5):1214-1223. doi: 10.1016/j.fertnstert.2013.08.012.

43. Phillips LN, Krishnamurti L, Rytting $\mathrm{H}$, Olson TA. Ovarian Sertoli-Leydig tumor after bone marrow transplant for sickle cell disease. Pediatr Blood Cancer. 2018 Nov;65(11):e27367. doi: 10.1002/pbc.27367.

44. Aumont C, Driss F, Lazure T, et al. Myelodysplastic syndrome with clonal cytogenetic abnormalities followed by fatal erythroid leukemia after 14 years of exposure to hydroxyurea for sickle cell anemia. Am J Hematol. 2015 Jul;90(7):E131-E132. doi: 10.1002/ajh.24010.

45. Luthra M, Bayne F. The seventh sickle cell nephropathy. Intern Med. 2010;49(23):2641.

46. Armenian SH, Chow EJ. Cardiovascular disease in survivors of hematopoietic cell transplantation. Cancer. 2014 Feb 15;120(4):469-479. doi: 10.1002/cncr.28444.

47. Bhatia S, Armenian SH, Landier W. How I monitor long-term and late effects after blood or marrow transplantation. Blood. 2017 Sep 14;130(11):1302-1314. doi: 10.1182/blood-2017-03-725671.

48. Tichelli A, Rovo A, Gratwohl A. Late pulmonary, cardiovascular, and renal complications after hematopoietic stem cell transplantation and recommended screening practices. Hematology Am Soc Hematol Educ Program. 2008:125-133. doi: 10.1182/asheducation-2008.1.125.

49. Demirci S, Uchida N, Tisdale JF. Gene therapy for sickle cell disease: An update. Cytotherapy. 2018 Jul;20(7):899-910. doi: 10.1016/j.jcyt.2018.04.003.

50. Kanter J, Walters MC, Hsieh MM, et al. Interim results from a phase $1 / 2$ clinical study of lentiglobin gene therapy for severe sickle cell disease. Blood. 2016;128(22):1176.

51. Ribeil JA, Hacein-Bey-Abina S, Payen E, et al. Gene therapy in a patient with sickle cell disease. N Engl J Med. 2017 Mar 2;376(9):848-855. doi: 10.1056/NEJMoa1609677.

This article meets the Accreditation Council for Graduate Medical Education and the American Board of Medical Specialties Maintenance of Certification competencies for Patient Care, Medical Knowledge, and Practice-Based Learning and Improvement. 